\title{
Laissez fair leadership role in organizational innovation: The mediating effect of organization structure
}

\author{
Heba Abu Rassa ${ }^{a^{*}}$ and Lawrence Emeagwali ${ }^{b}$
}

\begin{tabular}{l}
${ }^{a}$ AL-Ahliyya University, Jordan \\
\hline C H R O N I C L E \\
\hline Article history: \\
Received: November 12, 2019 \\
Received in revised format: No- \\
vember 302019 \\
Accepted: December 18, 2019 \\
Available online: \\
December 18,2019 \\
\hline Keywords: \\
Laissez Fair leadership \\
Administrative innovation \\
Technical innovation \\
Organizational structure \\
Jordanian health sector
\end{tabular}

\section{Introduction}

Despite the difference in their environments, all organizations seek to have success in their business and improvement in their performance so as to have the ability to compete and reach to what is best, special and differentiated. Studies have shown that leadership style in organizations is one of the most important factors affecting the success of its business, so the absence of a good, successful and qualified leadership is reflected negatively on the performance and production, and hinders the organization from achieving its goals (Robinson et al., 2008; Avolio et al., 2009; Dunne et al., 2016). Unlike what might be achieved in the presence of a successful, conscious and effective leadership. Hence, the issue of leadership is one of the topics that have attracted the attention of scholars and thinkers since ancient times. The interest in it in the modern administrative thought has increased as a result of increasing the need for effective leadership to deal with the developments, changes, challenges and problems that the organizations are witnessing on an ongoing basis. Many modern approaches of leadership emerged at the end of the seventh decade of the last century, which was found by Burns (1978). He also referred to transformational leadership patterns where it was known as "the ability of the leader to deliver the message of the institution and vision of the future clearly to the followers and motivate them by demonstrating high moral behaviors and build confidence and respect between the parties to achieve the objectives of the Foundation" (Murphy, 2005, p.131). The field of leadership is one of the most important areas affected by global changes both at country the organization level. The urgency of these changes and the challenges of excellence in leadership style and the transition of management methods to the global level have been imposed. Leadership is an important and necessary function to achieve organizational goals.

* Corresponding author

E-mail address: heba.rassa@gmail.com (H. Abu Rassa)

(C) 2020 by the authors; licensee Growing Science, Canada doi: $10.5267 /$ j.msl.2019.12.022 
Several studies have shown that leadership patterns are key factors affecting quality of work (Wong \& Laschinger, 2013). Leadership leads organizations to employ the substantial and appropriate transformations to achieve the organization's goals, set a vision for the future, seize potential opportunities and stimulate the employees' creative potential and increase their sense of commitment. Through their behavior, they can change the organization's culture of desired trends, create trust between them and subordinates promote a sense of justice among all employees and increase loyalty to the organization in which they work (Gillet et al., 2013).

This study seeks to examine the relationship between laissez leadership and organizational innovation in the Jordanian health sector.

\section{Theoretical Framework}

The position of a leader in the literature present as a key role in the organization, where Leadership develops subordinate attitudes and behaviors within the organization. Tannenbaum et al. (1961, p.24) define leadership as "the interpersonal influence, exercised in a situation, and directed, through the communication process, towards the attainment of specified goals." Out of this definition, leadership is presented as the impact over employees is considered as a communication pattern and perception of subordinate. In today's globalization, rapid technological development and the easiness of accessing information which any organization is facing (Yukl \& Mahsud, 2010; Hsiao et al., 2011) contribute to raise the need for better products and services, consequently to gain a competitive advantage, survival and sustainability in the market with maintaining a profit margin, organizations leadership are eager to find methods to impact their organizations to be innovative through employees creativity (Drucker, 1985; Woodman et al., 1993). Moreover, leaders develop their relationships with subordinate in order to trigger motivational reaction and develop corrective actions.

\subsection{Laissez Fair leadership and innovation}

There are mix results related to this dimension, James and Collins (2008) describe the laissez-faire leadership as passive style, where the leader is reluctant to influence subordinates' considerable freedom, to the point of handing over his/her responsibilities. In a sense, this extremely passive type of leadership indicates the absence of leadership. The study of Pasha (2017) points out that laissez faire is an expression of chaotic leadership or leadership of non-interference. The behavior of the leader is characterized by non-interference where the leader leaves the subordinates to behave as they wish and he/she delivers information to the subordinates and leaves them free to act. This pattern may reflect the inability of the leader to make a decision or lack of knowledge which leaves the organization without guidance, where workers feel lost, frustrated and disrespectful of the leader's personality, indicating that it is the least effective leadership style. Other studies find different results than the above such as Shaqqaa (2003) who shows that the laissez faire style was associated with a positive relationship with the level of administrative creativity of employees. Furthermore Zanati (1994) indicates a fundamental relationship between the behavior of the leader who adapt the idea of the subordinates' freedom of action and the subordinate's ability to think creatively. However, Al-Mazroui (1998) shows that the practice of the laissez faire model is moderate in the public sector; on the other hand, the practice of this pattern in the private sector is weak.

$\mathrm{H}_{1}$ : Laissez fair leadership has a significant impact on technical innovation.

$\mathrm{H}_{2}$ : Laissez fair leadership has a significant impact on administrative innovation.

\subsection{Laissez Fair leadership and organizational structure}

Al-Garaleh (2008) showed that change is a feature of leadership they can make in the organization, which involves bringing about change in the organizational structure. Making change is a key feature of transformational leadership. The change a transformation leader brings to the organization based on two primary directions, first in subordinates' behavior and attitudes and the second on organizational culture (Bass, 1985). The organizational structure, which is the context in which change occurs, has a moderate effectiveness on the change process. The more bureaucratic organization reflects more willingness form the staff to positively adapt change if the change is planned. The less bureaucratic organization the more willing the staff to change even if it is unplanned change (Voet, 2013). Al-Azmi (2006) showed in their study that the organizational structure, which lacks detail and clarification of powers and responsibilities, hinders the success of the leader. Therefore, one of the tasks of the leader was to recognize the need for change in the organizational structure (Al-Hawari \& Seyed, 2005). In some studies, there is a significant positive correlation between leadership and change management which includes making changes in the organizational structure. This indicates that the application of leadership through clear and understandable procedures and clear line of responsibility and authority leads to achieving competitive superiority over other rival organizations, also implementing strategic vision drawn by it. Based on the reviewed literature the authors hypothesize that:

$\mathrm{H}_{3}$ : Laissez fair leadership has a significant impact on organizational structure.

\subsection{Organizational structure and innovation}

Organizational structure involves the alignment of resources in a manner to develop and support specific logistics service innovation capabilities (Bergfors \& Larsson, 2009). In line with Pertusa-Ortega et al.'s (2010) approach, the current study 
combines the strategy-structure-performance (SSP) framework and the resource-based view (RBV) of the firm as the theoretical bases of the proposed model. Early SSP literature argued that changes in firm strategy will cause changes within the organizational structure so that strategy can be properly developed and higher performance achieved. However, further research suggests that successful strategies must be based on the organization's main distinctive capabilities and skills in order to achieve sustainable competitive advantage (Prahalad \& Hamel, 1990; Snow \& Hrebiniak, 1980). Therefore, organizational structure cannot be regarded exclusively as an element of strategic implementation. Instead, managers should consider it as an element of strategy formulation, as a resource, which can help improve performance (Pertusa-Ortega et al., 2010). Components of organizational structure are usually included in the firm resource category called organizational capital resources (Barney, 1991) or organizational resources (Grant, 1991). For example, Barney (1991) points out that organizational capital resources include a firm's reporting structure, formal and informal planning, controlling, and coordinating systems.

Based on understanding organizational structure as s resources that is available for leaders to use, we theorize the following:

H4: Organizational structure has a significant effect on technical innovation.

H5: Organizational structure has a significant effect on administrative innovation.

H6: Organizational structure mediates the relationship between Laissez fair leadership and Technical innovation.

\section{Methodology}

The research reported here employed a self-reported survey method to gather data from employees in 7 hospitals in Jordan. In total, 292 questionnaires were returned, out of which 22 were dropped as they included missing data or were judged to be unengaged responses. The survey items were developed from the literature. Three items were used from the Multifactor Leadership Questionnaire (MLQ) to measure Laissez fair leadership. Administrative innovation was measured using 8 items scale adopted from Reda (2003), while technical innovation was measured 6 items adopted from Taweel and Ismail (2013). Finally, organizational structure was measured using the scale used by Shammari (2017). All scale items were measured using a 5 point licker type scale with answers ranging from (1) strongly disagree to (5) strongly agree.

\section{Analysis and Findings}

Using statistical analysis tools enabled the researchers to evaluate the hypothesized relations. This was done in stages. First, the authors checked the gathered dataset through examining descriptive measures. This was followed by evaluating the dimensionality of the studied factors though conducting exploratory factor analysis. The structural equation modelling analysis conducted adheres to the recommended principles suggested by Gerbing and Anderson (1988). First a measurement model of the study variables was assessed and the second step involved testing the structural model. Using the maximum likelihood estimator, a confirmatory factor analysis (CFA) was evaluated. The assessment relies on how well the manifested variables mirror the theorized latent variables. Followed by employing structural model to check the validity of tested variables and goodness-fit indices. Thus, the relationships theorized were inspected for correlation effects.

\subsection{Validity and reliability}

Ahead of engaging in two step approach as defined above, the authors examined research data for dimensionality along with reliability. Here, the researchers' aim was to understand the factors as determined by the data. The objective was to understand the determinant factors as presented by the data. Consequently, exploratory factor analysis seemed to indicate that four constructs were present in agreement with the theorized variables. Additionally, Cronbach's alpha values were calculated and have shown values that met the threshold defined by Nunnally and Bernstein (1967) at 0.70 . Furthermore, cumulative variance explained values designated the reliability of the adopted scale for studying laissez fair leadership, organizational structure, administered and technical innovation. This has led to four factors with reflective items being put in groups together demonstrating four latent variables as needed by the measurement and structural model to test the theorized relationships. Henceforth, latent variables that were formulated in accordance with a priori theoretical basis have been used in developing confirmatory factor analysis in order to examine the measurement model of laissez fair leadership, organizational structure, administered and technical innovation. Fig. 1 below shows the measurement model.

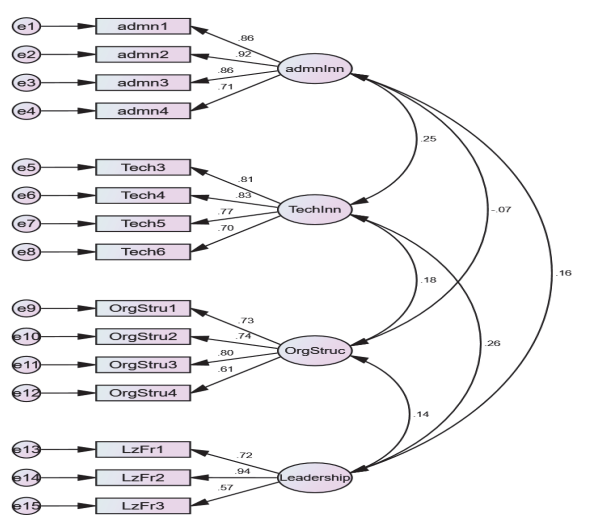

Fig. 1. Measurement model of the studied variables 
Convergent validity is achieved as all items in the Confirmatory Factor Analysis have above the 0.70 threshold recommended by Hair (2010). While discriminant validity is checked through covariance values of less than 0.50 between the latent variables. Additionally, the model fit indices for the model were deemed satisfactory as shown in Table 1.

Table 1

Model fit indices for the confirmatory factor analysis

\begin{tabular}{|c|c|c|c|}
\hline Measure & Estimate & Threshold & Interpretation \\
\hline CMIN & 109.114 & -- & -- \\
\hline DF & 84 & -- & -- \\
\hline CMIN/DF & 1.299 & Between 1 and 3 & Excellent \\
\hline CFI & 0.99 & $>0.95$ & Excellent \\
\hline SRMR & 0.044 & $<0.08$ & Excellent \\
\hline RMSEA & 0.033 & $<0.06$ & Excellent \\
\hline PClose & 0.952 & $>0.05$ & Excellent \\
\hline
\end{tabular}

\subsection{Hypothesis testing}

In order to test different hypotheses, the authors have tested a structural model as shown in Fig. 2. The model has demonstrated acceptable goodness of fit as evidenced by the model fit indices shown in Table 2.

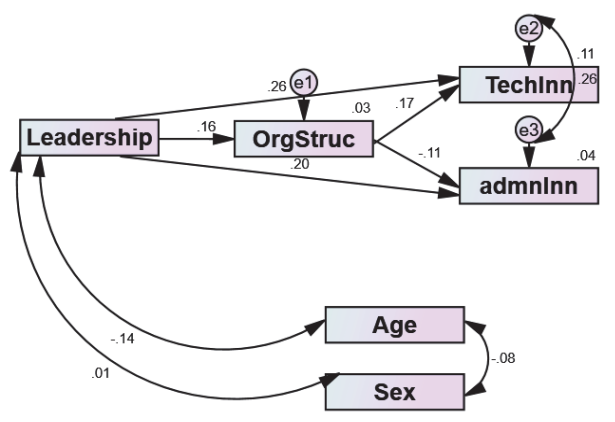

Fig. 2. Structural model of the study

Table 2

Model fit indices for the structural model

\begin{tabular}{|c|c|c|c|}
\hline Measure & Estimate & Threshold & Interpretation \\
\hline CMIN & 10.416 & -- & -- \\
\hline DF & 6 & -- & -- \\
\hline CMIN/DF & 1.736 & Between 1 and 3 & Excellent \\
\hline CFI & 0.94 & $>0.95$ & Acceptable \\
\hline SRMR & 0.05 & $<0.08$ & Excellent \\
\hline RMSEA & 0.052 & $<0.06$ & Excellent \\
\hline PClose & 0.407 & $>0.05$ & Excellent \\
\hline
\end{tabular}

The structural model investigated here reveals three results: first, laissez fair leadership impact on technical innovation was significantly positive $(\beta=.28, \mathrm{p}<.000)$, which meant that hypothesis one $(\mathrm{H} 1)$ found empirical support. Second, laissez fair leadership impact on administrative innovation was both positive and significant $(\beta=.20, p<.01)$, which meant that hypothesis two (H2) was empirically substantiated. Third, laissez fair leadership had a significant and positive impact on the Organizational structure among participants in this study $(\beta=.16, p<.00)$, thus finding support for the third hypothesis (H3). Fourth hypothesis testing has shown a positively significant effect $(\beta=.17, \mathrm{p}<.01)$ leading to supporting the fourth hypothesis. However, the fifth hypothesis of organizational structure effect on administrative innovation has not shown any significant effect. Results are shown in Table 3 as follows.

Table 3

Direct Hypotheses testing

\begin{tabular}{|c|c|c|c|c|c|}
\hline & Independent & dependent & Std Beta & Sig & Result \\
\hline H1 & Laissez fair Leadership & Technical Innovation & 0.26 & $* * *$ & Supported \\
\hline $\mathrm{H} 2$ & Laissez fair Leadership & Administrative Innovation & 0.2 & $* *$ & Supported \\
\hline $\mathrm{H} 3$ & Laissez fair Leadership & Organizational Structure & 0.16 & $* *$ & Supported \\
\hline $\mathrm{H} 4$ & Organizational Structure & Technical Innovation & 0.17 & $* *$ & Supported \\
\hline H5 & Organizational Structure & Administrative Innovation & -0.11 & Not sig & Not supported \\
\hline
\end{tabular}

Additionally, bootstrapping was set at 2000 iterations to assess the mediation outcome of the indirect path theorized of the effect of organiztioanl structure as a mediator between laissez fair leadership and technicla innovation. Social media through trust to evaluate its impact on customer loyalty to test hypothesis four is used. Bootstrapping was set to 2000 iterations, this 
has used bias-corrected intervals that are equated to $90 \%$ confidence interval. Results are shown in Table 4 below that inidicate the realtionship between laissez fair leadership and technical innovation is mediated by organzatrional structure. This offers support for the sixth hypothesis (H6).

Table 4

Mediation path estimates

\begin{tabular}{lcccc}
\hline Indirect path & Coefficient & Confidence interval Lower & Confidence interval Upper & P \\
\hline Laissez-Fair leadership & .05 & .02 & .11 & .01 \\
\hline
\end{tabular}

\section{Discussion}

The findings shown in this study have provided empirical support to the role of laissez fair leadership approach in supporting innovation in the health care context. All of the hypothesized relationships were supported apart from organizational structure effect on administrative innovation. To this end, our results have found empirical support from the literature for instance leadership was found an accountable force behind innovation in organizations (Jyoti \& Dev, 2015; Nusair et al., 2012). Moreover, leadership was found to positively affect organizational structure which complements the literature understanding of the relationship between leadership and organizational structure. Previously scholars have shown that organizational structure alongside leadership do affect organizational outcomes (Strese et al., 2016), while others argue for understanding how organizational culture shapes leaders' behavior (Valero, 2015). Results obtained here shown that organizational structure was receptive to change in the image of leaders within the organization, which represents a new insight in the leadership impact literature. Organizational structure requires utilizing assets available in a way that helps achieve organizational goals. In fact, Bergfors and Larsson (2009) argued for effect of organizational resources on innovation. In this study, organizational structure was found to be significantly responsible for enhancing technical innovation within health care institutions. This was in contrast to the effect on administrative innovation, which did not find any significant effect. Finally, organizational structure was found to have a mediating effect on the relationship between laissez fair leadership and technical innovation. This provides a timely update on the long-held views of organizational structure function as an enabler to achieve goals (Fredrickson, 1986). In this update, the authors have shown that organizational structure does in fact mediate the relationship between laissez fair leadership style and technical innovation in the Jordanian health sector. Practitioners can draw on this study of the Jordanian health sector, through expanding their knowledge of the effect laissez fair leadership style has on innovation. It transpires that innovation gains are reported when leaders engage in hands-free similar to that of laissez fair leadership style. As such, leaders are advised to let health sector employees express themselves more in their work, as this is found to have positive effect on innovation in hospitals.

\section{Limitations}

This research was conducted as a cross sectional study that relied on a relatively small sample size. Consequently, future research is encouraged to look at bigger sample sizes as well as conducting longitudinal studies that show how the observed phenomena fluctuate over time. Also, this study focused on laissez fair as one leadership style, hence, it suggested that other studies at other leadership styles must be performed. Finally, through our literature review it became apparent that other factors might play a moderating role on the theorized relationships, so we encourage researchers to add moderating variables such as organizational type to complement the model tested here.

\section{References}

Al-Azmi (2006). Transformational Leadership and its Relation to Administrative Creativity A Survey Study on Civil Personnel in the Ministry of Interior affairs. Unpublished Master Thesis, Naif University for Security Sciences, Saudi Arabia

Al-Garaleh (2008). Degree of Transformational leadership Practice for Directors of Public and Private Schools in the Capital Governorate from Teachers' Perspective. Unpublished Master Thesis, Mutah University, Karak, Jordan.

Al-Hawari \& Sayed (2005). The Transformational Leader and Change of the Future. Ain Shams Library, Cairo, Egypt.

Al-Mazroui (1998). Leadership Styles for Managers and Their Relationship with Employee Satisfaction: An Applied Study in Riyadh. Published Master Thesis, Nabef Academy for Security Sciences, Riyadh, Saudi Arabia.

Anderson, J. C., \& Gerbing, D. W. (1988). Structural equation modeling in practice: A review and recommended two-step approach. Psychological Bulletin, 103(3), 411.

Avolio, B. J., Reichard, R. J., Hannah, S. T., Walumbwa, F. O., \& Chan, A. (2009). A meta-analytic review of leadership impact research: Experimental and quasi-experimental studies. The leadership Quarterly, 20(5), 764-784.

Barney, J. (1991). Special theory forum the resource-based model of the firm: origins, implications, and prospects. Journal of management, 17(1), 97-98.

Bass, B. M. (1985). Leadership and performance beyond expectations. New York: Free Press.

Bergfors, M. E., \& Larsson, A. (2009). Product and process innovation in process industry: a new perspective on development. Journal of Strategy and Management, 2(3), 261-276.

Drucker, P. F. (1985). Entrepreneurial strategies. California Management Review, 27(2).

Dunne, T. C., Aaron, J. R., McDowell, W. C., Urban, D. J., \& Geho, P. R. (2016). The impact of leadership on small business innovativeness. Journal of Business Research, 69(11), 4876-4881. 
Fredrickson, J. W. (1986). The strategic decision process and organizational structure. Academy of Management Review, 11(2), 280-297.

Gillet, N., Fouquereau, E., Bonnaud-Antignac, A., Mokounkolo, R., \& Colombat, P. (2013). The mediating role of organizational justice in the relationship between transformational leadership and nurses' quality of work life: A cross-sectional questionnaire survey. International Journal of Nursing Studies, 50(10), 1359-1367.

Grant, R. M. (1991). The resource-based theory of competitive advantage: implications for strategy formulation. California Management Review, 33(3), 114-135.

Hsiao, Y. C., Chen, C. J., \& Chang, S. C. (2011). Knowledge management capacity and organizational performance: the social interaction view. International Journal of Manpower, 32(5/6), 645-660.

James, K. T., \& Collins, J. (Eds.). (2008). Leadership perspectives: Knowledge into action. Springer.

Jyoti, J., \& Dev, M. (2015). The impact of transformational leadership on employee creativity: the role of learning orientation. Journal of Asia Business Studies, 9(1), 78-98.

Murphy, L. (2005). Transformational leadership: a cascading chain reaction. Journal of Nursing Management, 13(2), 128136.

Nunnally, J. C., \& Bernstein, I. H. (1967). McGraw-Hill series in psychology. Psychometric theory. New York, NY, US: McGraw-Hill.

Nusair, N., Ababneh, R., \& Kyung Bae, Y. (2012). The impact of transformational leadership style on innovation as perceived by public employees in Jordan. International Journal of Commerce and Management, 22(3), 182-201.

Pasha, F. (2017). The attitude of administrative leaders towards the social responsibility of organizations: a case study of the Sonelgaz Society: Biskra. Thesis, unpublished doctor, University of Mohamed Khader, Biskra, Algeria.

Prahalad, C. K., \& Hamel, G. (1990). Core competency concept. Harvard Business Review, 64(3), 70-92.

Reda, H. (2003). Administrative innovation and its relation to job performance: An applied study on the security services at King Abdulaziz International Airport in Jeddah. Naif Arab Academy for Security Sciences, Riyadh, Saudi Arabia.

Pertusa-Ortega, E. M., Zaragoza-Sáez, P., \& Claver-Cortés, E. (2010). Can formalization, complexity, and centralization influence knowledge performance?. Journal of Business Research, 63(3), 310-320.

Robinson, V. M., Lloyd, C. A., \& Rowe, K. J. (2008). The impact of leadership on student outcomes: An analysis of the differential effects of leadership types. Educational Administration Quarterly, 44(5), 635-674.

Shammari, A. (2017). Job creation and strategic factors and their interaction with fundamental capacities and excellence in financial performance of service organizations: A comparative analytical study of a sample of Iraqi private banks for the Period 2001-2004. Al Ghari Journal of Economic and Administrative Sciences, 14(1), 201-228.

Shaqqaa, A. (2003). The relationship between leadership styles and the level of administrative creativity: a survey study for workers in the General Directorate of Passports in Riyadh. Unpublished Master Thesis, Naif Arab University for Security Sciences, Riyadh, Saudi Arabia.

Snow, C. C., \& Hrebiniak, L. G. (1980). Strategy, distinctive competence, and organizational performance. Administrative Science Quarterly, 317-336.

Strese, S., Meuer, M. W., Flatten, T. C., \& Brettel, M. (2016). Organizational antecedents of cross-functional coopetition: The impact of leadership and organizational structure on cross-functional coopetition. Industrial Marketing Management, 53 , 42-55.

Tannenbaum, R., Weschler, I., \& Massarik, F. (1961). Leadership and organization. New York, NY: McGraw-Hill.

Taweel, A., \& Ismail, R. (2013). The relationship between the types of technical innovation and the dimensions of competitive advantage: A field study in a selected group of industrial companies in Nineveh province. Iraqi Journal of Administrative Sciences, 26, 55-90.

Valero, J. N. (2015). Effective Leadership in Public Organizations: The Impact of Organizational Structure in Asian Countries. Journal of Contemporary Eastern Asia, 14(2).

Van der Voet, J. (2014). The effectiveness and specificity of change management in a public organization: Transformational leadership and a bureaucratic organizational structure. European Management Journal, 32(3), 373-382.

Yukl, G., \& Mahsud, R. (2010). Why flexible and adaptive leadership is essential. Consulting Psychology Journal: practice and Research, 62(2), 81.

Woodman, R. W., Sawyer, J. E., \& Griffin, R. W. (1993). Toward a theory of organizational creativity. Academy of management review, 18(2), 293-321.

Wong, C. A., \& Laschinger, H. K. (2013). Authentic leadership, performance, and job satisfaction: the mediating role of empowerment. Journal of advanced nursing, 69(4), 947-959.

Zanati, M. (1994). The effect of leaders' behaviors on the subordinate's innovative thinking. Trade and Supply Journal, 14(1), Tanta University, Tanta, Egypt.

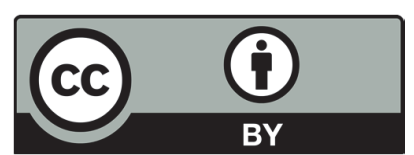

(C) 2020 by the authors; licensee Growing Science, Canada. This is an open access article distributed under the terms and conditions of the Creative Commons Attribution (CC-BY) license (http://creativecommons.org/licenses/by/4.0/). 